Gabriele Balbi, Nelson Ribeiro, Valérie Schafer and Christian Schwarzenegger

\title{
Digging into Digital Roots. Towards a Conceptual Media and Communication History
}

The digital age did not arrive from nowhere; it grew from its own roots and even the roots of previous ages. It already has its own narratives, made up of key players and heroes, brilliant technological ideas, disruptive devices, spectacular forecasting and sometimes epic failures. But over the past few years, scholars have started to narrate these histories in new ways, challenging heroic and teleological narratives and underlining multiple temporalities, stakeholders and cultural reappropriations. New histories of the digital age have also adopted a critical perspective, focusing on issues like global and equal distribution of digital tools (and in parallel digital inequalities and asymmetries of access), maintenance of digital networks, devices and content, co-shaping of digital technologies, and connection and disconnection in different societies. This has expanded our knowledge of the digital past and, of course, of the digital present.

Nevertheless, a chapter in these histories is often missing. The digital age is also made up of theoretical concepts which are mostly taken for granted and used "automatically" in the academic literature as well as in everyday life. Concepts influence the way we look at social reality, they shape how and in what terms we think and speak about the digital era, and they affect the ways we communicate and live. So, it is high time that we set a new trend in research that focuses on the concepts of the digital age. Indeed, by grounding research in concepts that are not properly problematized, we run the risk of making erroneous assumptions, which may prevent us from looking in the right direction and impair our ability to see beyond simplistic narratives about technology and its immediate impact on society. For example, in the 1990s and early 2000s, utopian visions of how the internet would usher in a new era of cultural democracy and undermine the power of dictators concealed the fact that the concepts of digital

Acknowledgements: We would like to express our sincere thanks to the ECREA Communication History Section, which is one of the main "roots" for this project, as well as Andreas Fickers, head of the $\mathrm{C}^{2} \mathrm{DH}$ at the University of Luxembourg, who strongly supported the project by welcoming it in the $\mathrm{C}^{2} \mathrm{DH}$ De Gruyter collection and helping to make it open access.

Ә Open Access. ( 2021 Gabriele Balbi, et al., published by De Gruyter. (c) BY-NC-ND This work is licensed under the Creative Commons Attribution-NonCommercial-NoDerivatives 4.0 International License. 
participation and digital disruption were scarcely problematized. This led to faulty suppositions about the potential of technology to expand democracy (as demonstrated by Curran 2012, Morozov 2011 and several other scholars), while also reflecting a failure to recognize that in previous eras, other media were also greeted by utopian discourses in their early days (Ribeiro 2015).

This book aims to help avoid this trap by analyzing and historicizing some essential concepts of the digital age that have been widely used in the literature. In the introduction, we set out what we mean by historicizing digital concepts and digging into their roots, we explain the structure of the book, and finally we advocate for a conceptual media and communication history - a new way at looking at communication technologies, practices, and consequences over time, starting from their concepts.

\section{Excavating the Roots of Digital Concepts}

What does it mean to devote a book to the roots of digital concepts? The etymologies of these two words in the Oxford English Dictionary can help explain our approach. The word concept is derived from the Latin conceptum (concipere, to conceive); it refers to something people are able to think of, something imagined in their mind, an idea or mental image, as encapsulated in the Middle French term concept. In philosophy, the word is used as a "mental representation of the essential or typical properties of something, considered without regard to the peculiar properties of any specific instance or example," meaning that a concept can be also considered as an ideal-typical image of the world.

Root has a different geographical origin: it is a borrowing from early Scandinavian, with Greek and Latin cognates. According to the Oxford English Dictionary, most etymologies indicate the botanical meaning: a root is "the part of a plant or tree, normally underground, which attaches it to the ground (or other supporting medium) and conveys water and nutrients from the ground to the body of the plant or tree." Figuratively, a root can also be the source, the origin or the cause of something, as well as the essence and the core of it. There is also an emotional dimension of roots, in the sense of strong links and attachments to ancestors (the word is indeed used to denote "a person or family considered as the source of a lineage").

Our project therefore aims to identify the origins, sources, lineage, and heritage of some of the most common mental images of the digital world. These images are often condensed in keywords or buzzwords that tend to be used widely, without any real reflection on their origins, development or even their 
real meaning. By offering a detailed analysis of 16 relevant concepts, this book attempts to dig into the innermost part of digital age, to reveal when and where these mental images emerged (some of them in analogue times), and how they have changed in recent decades.

This volume is not a dictionary, nor does it mirror the series named "Concepts of the Digital Society" in the journal Internet Policy Review (Katzenbach and Bächle 2019). First, this is because it is an edited volume, in which there is a dialogue between the chapters and an interrelated network of reflections on the digital age. Of course, the reader can focus on single chapters, but reading all of them together and in order (the old linear model of books) will provide a deeper sense of the project and may lead to the emergence of unintended themes or threads, some of which are suggested in the last paragraph of this introduction. Second, and more importantly, this is a historical book. History is undoubtedly the discipline which is most capable of embarking on such a long and difficult dig into the mental images of the innermost digital world. The historical approach will help analyze some of the relevant concepts of the digital age by following them through time and rediscovering their lost or persistent meanings and genealogies. Several of the most well-known and frequently discussed concepts in the digital age predate digitalization itself, as demonstrated in this book, and were previously used in the "analogue era." This may sometimes even challenge the opposition between analogue and digital, which in some cases is quite artificial (as Haigh 2019 and Sterne 2016 show). Other concepts were coined for the digital society but have changed and are continuously changing over time, in a clear demonstration of how meanings are social and cultural constructions. More generally, digitalization has had an impact on concepts: it has reintroduced or reinvigorated old concepts, or even changed their meanings. Concepts like networks, global governance and amateurism clearly have a pre-digital life, but they have been incorporated so fully into digital semantics that, when we think about them today, we immediately link them to the realm of digitalization.

With this book we aim to highlight the persistent changing nature of digital concepts (and any concepts) as a result of cultural reappropriation and transformation over time, and to analyze the flexibility of what we tend to see as frozen mental images. We are aware that concepts tend to change slowly, but they always change over time (see for example Bay 2017 and Hösl 2019 on the semantics of the internet). Since history is the discipline of continuity and change par excellence, this book aims to equip researchers in media and communication studies, general history, digital studies and related disciplines with flexible lenses to understand the present. A root always carries water and nutrients from 
the ground to the surface plant, and digital history can similarly irrigate the digital present.

Finally, this book is rooted in history at several levels, as it also tries to provide a brief overview of the evolution of digital historiography for each specific concept. The readers will find essential literature reviews in each chapter and a state of the art of the ways in which scholars from different disciplines have treated each notion. This is a chance to rediscover and discuss some seminal approaches, such as those by McLuhan (1964), Negroponte (1995), Castells (1996), Turkle (2011) and several other digital champions.

To sum up, by historicizing digital concepts we mean identifying their roots and tracing the changes and developments they - or the phenomena they describe - have gone through over time and in terms of historiography. Historicizing is a way of complexifying, contextualizing, and entwining technological visions with mental images, social appropriations, and political and economic discourses.

\section{Structure, Content, and Viennese Roots}

The idea of this book emerged during a lunch in one of the most famous Viennese restaurants for Wiener schnitzel. This lunch was on September 11, 2019 and it predated the ECREA Communication History Section workshop "Jeopardizing Democracy throughout History," held in Vienna and co-organized by the Austrian Academy of Sciences. At this workshop, the three elected section chairs and former chair Nelson Ribeiro wanted to create a symbolic bridge connecting past and present. At the same workshop, the first tangible publication by the Communication History Section, set up in 2010, was presented (Arnold, Preston, and Kinnebrock 2019), and so we decided to engage the section members in a new project. A call for chapters was later launched and disseminated via the usual academic channels and mailing lists. Consequently, we received further applications and we were able to make a selection from an ample base, complemented by experts that we contacted directly as editors to write specific chapters. In other words, the book emerged on a rolling basis, but as a rounded and consistent project. The result of this long process is a series of contributions from well-known scholars, coming from or working in Austria, Belgium, France, Germany, Ireland, Israel, Italy, Japan, Luxembourg, the Netherlands, Portugal, Sweden, Switzerland, the United Kingdom, and the United States.

The reader may feel that some notions are missing and point out some silences. In 2016, no fewer than a hundred notions relating to digital civilization were briefly addressed in a book edited by Jean-Paul LaFrance (2016). And new notions 
have already appeared since. However, our goal was to allow for a detailed analysis of concepts, relying on a strong diachronic perspective, historical sources and careful "gardening" of the roots, which made exhaustive coverage both impossible and undesirable. The book therefore also paves the way for further analysis and potentially one or more additional volume(s), but it already provides strong outputs in three directions that reflect the main sections of the book: Technologies and connections, Agency and politics and Users and practices.

Section one (Technologies and connections) is composed of five chapters focusing on the foundations and underlying infrastructures, as well as the connections and interactions of the digital age. This section reconstructs the paths that have led to the merging and integration of technologies. It starts from a period of functionally differentiated tools, technologies and devices and proceeds to a time when technologies and media seem to be overlapping and multiplying more than in any other previous age. In this latter era, prefixes such as inter-, multi-, netdenote a connecting and connective dimension of digitalization per se. Chapter 1 , by Massimo Rospocher and Gabriele Balbi, is about one of the most symbolic and obsessively repeated concepts in digital literacy: networks. The authors reconstruct a history of road, postal, telecommunications, transportation, and broadcasting networks over the centuries, identifying two persistent dimensions that also characterize the digital age: the infrastructural and material aspect underlying all types of network, on the one hand, and the ability to create communities of people connecting over the new infrastructure, on the other. John O'Sullivan and Leopoldina Fortunati focus on the concept of media convergence, tracing its ramifications in cultural, technological, market and policy terms. By examining case studies such as newspaper supplementation and add-ons in the nineteenth century and the relationship between the telephone and broadcast media in the twentieth century, they rediscover processes of combination and adaptation in pre-digital media and the need to recognize them if we are to understand equivalent phenomena in the digital era. Katie Day Good retraces the origins of the term multimedia by focusing particularly on educational uses and tracing the emergence of a multimedia sensibility in US education in the interwar years. The chapter also demonstrates how early educational discourses and experiments helped pave the way for corporate and cultural visions of multimedia.The author further shows that not all concepts age well and describes how, with the progress of digitalization, the once progressive promise of multimedia began to feel dusty and the concept lost intellectual trajectory. Chapter 4, by Benjamin Thierry, is about interactivity. When this concept emerged in the 1960s, it was linked to computers and used in several fields like ergonomics, computer science, and psychology. It refers to the relationship between humans and digital (or analogue) machines, a relationship which the author believes has constantly changed 
over time: from a simple dialogue to a broad framework for interpreting the digital world. Paolo Bory, Simone Natale, and Dominique Trudel scrutinize artificial intelligence. Their chapter reconstructs the historiographies of AI, starting with cybernetics and human-computer interaction, then irrigated by science fiction and gaming perspectives, and culminating in the pervasiveness we see today. They conclude by suggesting that AI historiography can give us new insights into the theoretical foundations of communication and media studies in a broad sense.

Section two of the book is entitled Agency and politics. The five chapters in this section look at digital concepts related to policy and the way in which cultural interventions have shaped the contemporary digital landscape. None of the five concepts is new or was created in the digital age, but all are emblematic of our times. The battle for the control and regulation of the internet is a matter of global governance. The process of generation, interpretation, and transformation of data as a means of understanding, describing, and predicting reality is called datafication. The idea of fake news has been obsessively alluded to by Donald Trump and other populist leaders but has also been extensively used in scholarship. It refers to the dissemination and spread of disinformation as well as the strategic discrediting of news sources to diminish citizens' trust in journalism and media outlets. Echo chambers refer to personalized information bubbles as alleged boosters of social fragmentation and polarization, which supposedly only resonate with preformed and coherent opinions. Finally, activism has re-emerged in the digital era with new and specific characteristics, often accompanied by premature claims that new forms of protests and activist participation were only rendered possible by the internet and digital communication. These concepts summarize processes that are shaping our everyday life.

In their chapter, Francesca Musiani and Valérie Schafer focus on the history of global governance, from the telegraph to the internet. Media governance at worldwide level is not a digital invention, and back in 1865 the first international organization was founded to regulate (and govern) telegraphy: the Telegraph Union, today the ITU. A historical approach to the topic may help both to flesh out continuities through time and to historicize internet governance, since the concept has evolved in recent decades with the creation of other powerful international organizations like ICANN and WSIS. In Chapter 7, Erik Koenen, Christian Schwarzenegger, and Juraj Kittler approach the notion of data(fication) from a long-term perspective. They analyze how, long before the "digital revolution," data and datafication were already producing exclusive arrangements of infrastructures and ordering knowledge. They also retrace shifting and persistent institutions for data collection and processing and governance of access, while providing an analytical matrix to identify enduring questions and 
changing answers through the ages. Monika Hanley and Allen Munoriyarwa address one of the most misused concepts of the past decade: fake news. As the chapter subtitle makes clear, this is a new term but a very old practice that has been prevalent since societies first started to share information. Nevertheless, the acceleration of communication distribution and new spaces and platforms that can be used to spread disinformation are changing its meaning, as contemporary populism and the Covid-19 pandemic have demonstrated. Fake news is a prototypical example of how (digital) concepts are constantly acquiring new semantic meanings and how terms coined in public debate or popular discourse can infiltrate and dominate scholarship. In Chapter 9, Maria Löblich and Niklas Venema historicize echo chambers. On the surface this concept appears to refer to recent changes in the digital media environment, but the authors demonstrate how it replicates past concerns about the fragmentation of public discourse. The history of echo chambers is indeed full of simplistic assumptions and unjustified worries about naive media audiences and "wrong" uses: from the print press in the nineteenth century to cinema and broadcasting in the twentieth century, the media have often been seen as forces serving both the aggregation and the fragmentation of the public sphere. Digital media are no exception, but the diversified communication offerings constituting people's personal blend of information raise unprecedented challenges. The last chapter in this section is written by Emiliano Treré and Anne Kaun and engages with the notion of digital media activism. The chapter argues for the adoption of both a historical and a contextualized ecological perspectives. In their journey through the history of digital activism, they also demonstrate how the concept has been "constructed" by parallel ideas and terms used to emphasize particular technological aspects or to foreground particular modes of participation.

The third and final section of the volume looks at six digital concepts that are indicative of Users and practices often considered characteristic of the digital age. This section is related to user experiences in a broad sense and to new practices from below in the digital realm. These practices also have their own histories. The concepts in this section have become popular in recent decades because they embrace a new relationship between media and their users, especially the fact that users are increasingly "active" and actively involved in the generation and circulation of mediated content. Amateurism, user-generated content and fandom, for example, all refer to different ways in which users participate in the production of digital content or engage with existing content circulating in networks in creative ways. Other concepts are related to renewed experiences and practices by users, like telepresence or feelings of loneliness, both of which have a long history. Finally, the concept of authenticity diverges somewhat and considers the specific case of historians as users. Even historians 
have to take into account how digitalization has changed their field, methods, and tools and to adopt new practices, especially digital hermeneutics, which our approach to concepts may also help deepen.

In Chapter 11, Jérôme Bourdon enlarges the meaning of (tele)presence to include historical forms of presence from a distance, like painting and correspondence but also telegraphy, newspapers, and broadcasting. Taking into account non-digital media and past experiences, it demonstrates how presence at a distance has created connections with a variety of creatures, both humans and non-humans, but always in some way humanized. This pre-digital past of the concept also involves several interlinked related concepts and semantic elements such as liveness, synchronicity, social presence, and virtual reality and their persistence across technologies and times. Edward Brennan historicizes the idea of digital loneliness. Paradoxically, digital media, which are defined as means of connection with the potential to link people, have also introduced and even promoted new forms of isolation and new feelings of loneliness. The chapter contextualizes digital loneliness as the latest manifestation of the type of polarized "hopes and fears" discourse that cyclically greets new communication tools, while also approaching it as a cultural phenomenon shaped by longterm historical processes. In Chapter 13, Susan Aasman, Tim van der Heijden, and Tom Slootweg explore the multiple meanings of amateurism in the ages of film, video, and digital technologies. In the current digital age, media amateurs seem to have taken over a large part of cultural production and revised traditional hierarchies between professionals and amateurs. But the concept is older and more complex: the associated mental images and meanings emerged in the late nineteenth century, if not before. In addition, in this chapter, the authors propose to develop an analytical tool to identify various amateur modes of practice, a kind of ontology of amateurism which requires a historical perspective. Göran Bolin deals with the related concept of user-generated content, also known by the acronym UGC - concepts are sometimes real "brands", like this acronym shows. Popularized in the early 1990s to describe media content produced by users outside the traditional professional media institutions, UGC gained widespread popularity around 2005. But the chapter also situates UGC in the longer history of media production and suggests explanations for why the concept rose to popularity when it did and why it has been met with increasing criticism. In Chapter 15, Eleonora Benecchi and Erika Wang historicize fandom and look at the difference between Eastern and Western perspectives. Even though fandom has changed in the digital age, the authors argue that there has been an overestimation of the novelty of modern fan communities (this is quite typical of anything digital in media and communication research), since digital fan practices can often be traced back to the pre-digital era. Furthermore, fandom and fans 
themselves are defined in several different ways, as the comparison between Western and Eastern cultures shows. In other words, this chapter demonstrates how a comprehensive history of any digital concept should be transnational and should also include meanings and ideas from the analogue era. In the last chapter of the book, Andreas Fickers proposes a new interpretation of a key concept of the digital era: authenticity. Instead of considering it as an apparent rise in authentic or less intermediated digital communication, the chapter investigates how digitality has affected the idea, concept, and meaning of the authenticity of historical sources. The chapter is particularly geared towards historians, as it advances a critical understanding of how digital infrastructures, tools, and technologies affect historical methodology. Digital concepts can also influence specific and narrow fields of work, and Andreas Fickers provides a clear example of this. The chapter symbolically echoes the name of the series, Studies in Digital History and Hermeneutics, thereby creating a bridge with future books in the series.

\section{New Roots to be Explored}

As already mentioned in the previous section, this book is intended to be more than the mere sum of its chapters. Just as roots can grow above the earth or run beneath it, there are some hidden and some more visible links among the concepts in this collection and the chapters historicizing them. In particular, the book proposes an agenda for how to approach media and communication studies through concepts. In this part of the introduction, we identify the main topics of this agenda, but of course we are eager to know if our future readers will find other more relevant issues.

First, several chapters address digital concepts from a longue durée perspective, making reference to the French historian Fernand Braudel (1960). In a telling metaphor, Braudel claims that seas are characterized by three degrees of movement: quasi-static deep abysses; undersea currents, which are moving and deep down; and constant surface ridges. Historical research should examine all three dimensions together but should especially focus on the first and second because it is only over the long term (longue durée in French) that the deepest and most meaningful social changes take place. What does it mean to study the longue durée of digital concepts? It means studying them even before they were commonly used, when they had different names, or even when societies were not able to name them at all. It means studying digital concepts from a diachronic perspective, looking at the present as just one of many options and maybe not the most enduring or meaningful. It also means recognizing how the frenetic daily 
pace of digital innovation does not correspond to the slow and uncertain pace with which ideas and mental constructs evolve. The absorption of concepts in the mentalities and socio-cultural fabric of societies is a much slower process. The roots of apparently new concepts like networks, fake news, data(fication), and telepresence have grown deeper and deeper over the centuries and have evolved hand in hand with the development of human cultures and societies.

A second and related thread in the book has to do with repetitions, patterns over time, and therefore once again with the temporalities of digital concepts. Historicizing is more than just looking back. It enables us to trace continuity and change, to pinpoint shifts and identify differences in the meaning of concepts. Historicizing does not only mean following a concept back to its seed and its roots; it also means retracing this path and applying concepts with a greater understanding of the nuances they have carried through time, their dominant meaning at a given point in time, connotations they may have shed at other moments or may still omit today.

We often tend to emphasize the uniqueness of the world we live in. This tendency is known as "presentism," "chrono-centrism" or "newness" (see for example Fischer 1970), and it has often been embraced by media and communication studies (for a critique see the seminal work by Marvin 1989). We tend to think that digitalization is an exceptional phenomenon (this attitude is also referred to as "digital exceptionalism"), that digital media are disruptive and unprecedented innovations which have radically changed the way we communicate and, consequently, the way we live (for a critique, see Balbi and Magaudda 2018; Menke and Schwarzenegger 2019). The same goes with digital concepts: digitalization must have produced new ways of thinking, with minor or no ties with the past, and so must have introduced "exceptional" concepts. This is simply wrong, and it is always refreshing to look at the continuities in which new media and technologies of communications were envisaged over time, how related concepts were born and how they have evolved. Networks have always had infrastructural and material dimensions, as well as the ability to create and destroy communities. The collection, distribution and conservation of data have always gone hand in hand with political, economic and symbolic power. People felt lonely when watching TV in their living rooms way before digitalization. Fans were considered "weird" and liminal audiences even when they exchanged paper newsletters to discuss their idols.

Very often these reflections on new media and communication technologies are stereotypical and recurrent: if we borrow the words of Umberto Eco (1964), media are often judged with a polarizing vision which he called "apocalyptic" and "integrated." Apocalyptic visions are negative, looking at the development of new media as a dangerous phenomenon for societies, while integrated visions 
tend to underline the benefits societies will have in using them. Eco wrote his book mainly focusing on the polarization of discourses around television in the 1960s, but the same claims can be adapted to digital media, digitalization, and digital concepts. Before the 2000s, digital visions were mainly positive and "integrated": think about concepts like collective intelligence and frictionless capitalism, as well as the terms user-generated content and interactivity, included in our book. After the 2000s, maybe because of the burst of the internet bubble or maybe because of the rise in surveillance, there was a critical or "apocalyptic" turn in the ways we think about digital technologies. Consequently, concepts like fake news, echo chambers and digital loneliness (as well as others not included in this book such as digital solutionism and digital surveillance) have emerged. The book reveals how stereotypical ways of looking at communication and media re-emerge and persist over time, medium by medium, but also how concepts are born of their time and their meanings may change according to shifts in the political, economic, and cultural zeitgeist. Repetitions, patterns, and temporalities of digital concepts are lenses to take away from this book. They are closely intertwined and are prerequisites for the third way we suggest approaching the book, which may be the most relevant in theoretical terms.

Media and communication history is often focused on messages, technologies, politics, economics and other related aspects. This book proposes to launch a conceptual media and communication history, scrutinizing how concepts in the field of media and communication develop over time. This is also why we chose to use the term "concepts" for this volume, rather than keywords or ideas. A history of concepts emerges at the crossroads where keywords and a history of ideas intersect. In our understanding, keywords highlight what is considered as the shared and defining knowledge at the time of writing or editing a project. As Raymond Williams noted in his pioneering work on the keywords of culture and society, they reflect not the dictionary or glossary of a particular academic subject, but the "shared body of words and meanings in our most general discussions" (Williams 1983, 15). Decades later, the spirit of Williams' seminal publication was evoked again in the anthology Digital Keywords edited by Benjamin Peters. Following in Williams' footsteps, the book by Peters explains that keywords are indicative of social change and transformation in how we speak and think. Keywords can serve as a literal key and open up particular perspectives on the world, but they will only do so "if the work [they do] can be distinguished from and then connected to other terms - a keyword must serve as a discrete operator in a larger semantic system" (Peters 2016, xx). A key in this sense is used both to open and to lock doors: "They stand sentinel to the halls of knowledge and power" (Peters 2016, xiii). In the discussion of keywords, the role of language is paramount, as is the 
core question of how it shapes, moves, and affects ways of being in the current media environment and what is hidden or revealed by the vocabulary used (Peters 2016).

A history of ideas is even broader and more general, as it sets out to trace theoretical ideas and perceptions of the world and the epistemic grounds on which they have been built through the ages, regardless of the verbal expression they find at a given moment and the ways in which particular ideas unfold in debates at specific times. Ideas can come in different shapes and sizes, and similar ideas can exist in different ages as well as in different cultural and geographical settings. However, it is in concepts that ideas are manifested - ideas travel loosely, but in concepts they take shape and form. Concepts give names to abstract ideas and hence become fundamental building blocks of thoughts and perceptions. The history of concepts allows us to identify how different ideas have manifested themselves in various (key)words over time and to find instances where a new term does not signify a new conceptual idea as well.

Conceptual history (Begriffsgeschichte) has a long theoretical tradition dating back to at least the 1930s in the German historiography, and especially to the work of Otto Brunner (Vogelsang 2012). We refer to this tradition, but we also propose something different for media and communication studies. Conceptual history is traditionally linked to semiotics and linguistics, since the meanings of concepts can be found in their semantics, in their definitions or in words and discourses. This literary approach, quite similar to the keyword approach outlined above, is not the focus of this book. Despite the fact that etymologies are relevant (and this should be clear even towards the end of this introduction), you will not find semantic trajectories of all the concepts. This book is not an etymological history of digital concepts.

We embrace a more extensive and social-historical approach to digital concepts, following in the footsteps of the German historian Reinhart Koselleck. He famously theorized the relationship between social history and conceptual history in two texts (Koselleck 1989, 2004), but we have particularly drawn insights from the one published in the book Future Pasts. According to Koselleck (2004, 76), "Without common concepts there is no society, and above all, no political field of action. Conversely, our concepts are founded in sociopolitical systems that are far more complex than would be indicated by treating them simply as linguistic communities organized around specific key concepts.” Adapting this idea for our book, there is no digital age without its concepts and, conversely, those concepts are not merely a linguistic reality but also a societal one.

Conceptual history helps us understand the political, economic, and social struggle to impose new ways of thinking. We have already said that this book tries to retrace the histories of concepts even before they were created or imagined, and 
Koselleck claims that "concepts no longer serve merely to define given states of affairs, but reach into the future. [. . . ] positions that were to be secured had first to be formulated linguistically before it was possible to enter or permanently occupy them" (Koselleck 2004, 80). Concepts have politics and stakeholders fighting to impose them. This is especially relevant in the digital age, when several of the key concepts conceal power, economic interests and cultural hegemony.

Conceptual history is also a method for source criticism, and Otto Brunner $(1946,187)$ proposed that we look at the past through a terminology derived from sources themselves, "so that the meaning of these sources may be correctly interpreted with the help of these concepts." When engaging in media and communication history, we should always ask ourselves if a nineteenth century concept that has apparently lasted over time really means the same today. This is a difficult but necessary exegesis of the sources we use and can help us to avoid incorrect historical parallelisms and, in the final analysis, anachronism. In every conceptual history, there is a risk of overusing current mental categories to analyze past concepts, just as there is also a risk of negating the particularities of the current moment when applying well-established concepts to them. This is a paradox for a conceptual media and communication history: it can cause us to overstate change while underestimating continuity or, on the contrary, to overemphasize persistence and negate transformations in the concepts we use. We are conscious that this is a risk we took when we started editing this book, but we think that there would be more at stake if we had failed to do so. Furthermore, the chapters in the volume are intended to start conversations rather than end them.

Conceptual history focuses on "persistence, change and novelty" (Koselleck 2004,84 ) and takes the diachronic perspective very seriously. Concepts that appear not to have changed for a long time may actually have acquired an entirely new meaning, but their redefinition may have been overlooked or unrecognized. Moreover, "Concepts not only teach us the uniqueness of past meanings, but also contain structural possibilities, treating the concatenations of difference invisible in the historical flow of events" (Koselleck 2004, 91). Concepts can reveal the contemporaneity of non-contemporaneous events, linking them at different points in time.

Applying these ideas to our field, as already mentioned, with this book we propose to launch a conceptual media and communication history of the digital age. This is a first attempt to make digital concepts (and not devices, gurus, politics, business, etc.) central to reflections on the digital age. It is also a plea for concepts to be understood in the social context in which they emerge and develop, as well as a means of urging scholars to consider shifting realities and mentalities and different ways of envisaging and imagining media over time. 
This approach is different from that of conventional media history and can bring to light new narratives regarding media and communication. The difference is that research is not guided merely by phenomena related to media and communication but by how we (used to) think about them, approach them and make sense of them. For instance, looking at media convergence in its analogue forms, starting with the press, the telephone and broadcasting means revisiting established assumptions of digital media convergence and thereby redefining an idea that is often taken for granted. A conceptual history of artificial intelligence can help us to reconsider and discuss the theoretical foundations of communication and media studies as a whole. Examining the concept of fandom calls for sensitivity towards transnational and transcultural differences and illustrates how conceptual histories can bring to light a global perspective which is somewhat rare in media historiographies. The same concept can have different meanings - Koselleck $(2004,85,90)$ calls this a "plenitude" or "diverse strata" of meaning - in different cultures and geographical areas; it can be evaluated according to different social and academic normativity and hence guide research in various ways. Concepts can also travel in peculiar ways from one cultural setting to another, re-enter via different neighboring fields and find fresh reception and application in another context (Pooley and Schwarzenegger 2017).

A conceptual media and communication history should therefore also highlight how concepts emerge, become hidden, are transformed and re-emerge over time. Concepts are like streams which can flow under the surface of social recognition for a long time and burst forth abruptly at specific moments in time. Artificial intelligence is a typical concept that has gone through summers of visibility and obscure winters (Natale and Ballatore 2020), but this also applies to concepts such as telepresence, multimedia, and interactivity, which were all very popular in the 1990s and 2000s but have since declined in favor of others. Concepts always influence each other, both diachronically and synchronically, and digital concepts are no different. Concepts can even shape the future. Digital concepts symbolize political and economic tensions and negotiations, and if powerful stakeholders want to reuse and re-semanticise them for their purposes in the future, they will probably be given a second birth. French scholars André Gaudreault and Philippe Marion (2005) have introduced the "double birth model" to describe and explain the reemergence of media technologies over time, but this model can be applied to concepts as well. Furthermore, processes of reinvention and re-birth always entwine different concepts, especially when their meanings seem to be written in stone, well defined and accepted. So, historicizing digital concepts which are presumably expressions of a current state of affairs and disentangling them from the digital realm allows us to straighten out their roots and trace them back to previous 
eras. This can help scholars avoid historical blindness and make them less receptive to suggestions of exceptionalism.

A conceptual media and communication history can be beneficial for "traditional" media and communication history and also for media and communication research in a broader sense, showing both where the political, economic, sociocultural and technological mental images applied to our media come from and also how concepts in media and communication can be changed, used, instrumentalized and co-shaped over time, how different cultures interpret them, and their ascending and declining popularity. Concepts are always fragile and, as expressed in the famous poem Soldiers by the Italian Giuseppe Ungaretti (1918), they are "like leaves on the trees in autumn."

\section{References}

Arnold, Klaus, Preston, Paschal, and Susanne Kinnebrock, eds. European Communication History Handbook. Hoboken: Wiley, 2019.

Balbi, Gabriele, and Paolo Magaudda. A History of Digital Media. An Intermedia and Global Perspective. New York: Routledge, 2018.

Bay, Morten. "What is 'internet'? The case for the proper noun and why it is important. Internet Histories 1, no. 3 (2017): 203-218.

Braudel, Fernand. "History and the social sciences: The long duration." American Behavioral Scientist 3, no. 6 (1960): 3-13.

Brunner, Otto. Land und Herrschaft: Grundfragen der territorialen Verfassungsgeschichte Südwestdeutschlands im Mittelalter. Brünn: Rohrer, 1946.

Castells, Manuel. The rise of the network society. Malden: Blackwell, 1996.

Curran, James. "Rethinking the Internet." In Misunderstanding the Internet, edited by James Curran, Natalie Fenton, and Des Freedman, 3-33. London - New York: Routledge, 2012.

Eco, Umberto. Apocalittici e integrati. Milan: Bompiani, 1964.

Fischer, David H. Historians' Fallacies: Toward a Logic of Historical Thought. New York: Harper Torchbooks, 1970.

Gaudreault, André, and Philippe Marion. “A Medium is always born twice.” Early Popular Visual Culture 3, no. 1 (2005): 3-15.

Haigh, Tom. Exploring Early Digital. Berlin - Heidelberg: Springer, 2019.

Hösl, Maximilian. "Semantics of the internet: a political history." Internet Histories 3, no. $3 / 4$ (2019): 275-292.

Katzenbach, Christian, and Thomas C. Bächle. "Defining Concepts of the Digital Society." Internet Policy Review 8, no. 4 (2019).

Koselleck, Reinhart. "Social History and Conceptual History." International Journal of Politics, Culture, and Society 2, no. 3 (1989): 308-325.

Koselleck, Reinhart. Futures Past: On the Semantics of Historical Time. New York: Columbia University Press, 2004. 
LaFrance, Jean-Paul, ed. 100 notions sur la civilisation numérique. Les éditions de l'Immatériel, 2006.

Marvin, Carolyn. When Old Technologies Were New: Thinking About Electric Communication in the Late Nineteenth Century. New York - Oxford: Oxford University Press, 1989.

McLuhan, Marshall. Understanding Media: The Extensions of Man. New York - London: McGraw-Hill, 1964.

Menke, Manuel, and Christian Schwarzenegger. "On the Relativity of Old and New Media: A Lifeworld Perspective." Convergence: The International Journal of Research into New Media Technologies 25, no. 4 (2019): 657-672.

Morozov, Evgeny. The Net Delusion. How not to Liberate the World. London: Allen Lane, 2011.

Natale, Simone, and Andrea Ballatore. "Imagining the thinking machine: Technological myths and the rise of artificial intelligence." Convergence: The International Journal of Research into New Media Technologies 26, no. 1 (2020): 3-18.

Negroponte, Nicholas. Being Digital. New York: Knopf, 1995.

Peters, Benjamin. “Introduction.” In Digital Keywords: A Vocabulary of Information Society and Culture, edited by Benjamin Peters, xiii-xiv. Princeton: Princeton University Press, 2016.

Pooley, Jefferson, and Christian Schwarzenegger. "Faulty Reception: The Institutional Roots of U.S. Communication Research's Neglect of Public Sphere Scholarship." In Kommunikationswissenschaft im internationalen Vergleich, edited by Stefanie AverbeckLietz, 317-345. Wiesbaden: Springer Fachmedien Wiesbaden, 2017.

Ribeiro, Nelson. "The Discourse on New Media: Between Utopia and Disruption.” In Theorien des Medienwandels, edited by Susanne Kinnebrock, Christian Schwarzenegger, and Thomas Birkner, 211-230. Köln: Herbert von Halem Verlag, 2015.

Sterne, Jonathan. "Analog." In Digital Keywords: A Vocabulary of Information Society and Culture, edited by Benjamin Peters, 31-44. Princeton: Princeton University Press, 2016.

Turkle, Sherry. Alone together: Why we expect more from technology and less from each other. New York: Basic Books, 2011.

Vogelsang, Kai. “Conceptual History: A Short Introduction.” Oriens Extremus 51 (2012): 9-24. Williams, Raymond. Keywords: A Vocabulary of Culture and Society. London: Fontana Press, 1983. 